Accepted refereed manuscript of: McDougall CW, Hanley N, Quilliam RS, Needham K \& Oliver DM (2020) Valuing inland blue space: A contingent valuation study of two large freshwater lakes. Science of The Total Environment, 715, Art. No.: 136921

DOI: https://doi.org/10.1016/i.scitotenv.2020.136921

(C) 2020, Elsevier. Licensed under the Creative Commons Attribution-NonCommercial-NoDerivatives 4.0 International http://creativecommons.org/licenses/by-nc-nd/4.0/

\title{
Valuing inland blue space: A contingent valuation study of two large freshwater lakes
}

Craig W. McDougall a, Nick Hanley ${ }^{\text {b }}$, Richard S. Quilliam ${ }^{\text {a }}$, Katherine Needham ${ }^{\text {b }}$, David M. Oliver ${ }^{\text {a }}$

${ }^{\text {a }}$ Biological \& Environmental Sciences, Faculty of Natural Sciences, University of Stirling, Stirling, FK9 4LA, UK

b Institute of Biodiversity Animal Health and Comparative Medicine, University of Glasgow, Glasgow, United Kingdom

Craig W. McDougall corresponding author: c.w.mcdougall@stir.ac.uk

Highlights:

- The contingent valuation (CV) method estimates economic values of non-market goods.

- A nationwide CV survey was used to value the protection of lakeside space in Scotland.

- Mean WTP per household per year was £12.06 for Loch Lomond and £8.44 for Loch Leven.

- Household income and location relative to the lake are significant determinants of WTP.

- Payment consequentiality has mixed effects on the valuation gap. 


\section{Abstract}

Water bodies, or blue spaces, offer a range of health and well-being benefits. Many of these benefits occur in waterside spaces and do not require direct water contact. For example, non-water based physical activity (e.g. walking and running) or reduced stress as a result of viewing water from a distance. However, research dedicated to understanding the economic impact of changes to freshwater ecosystems predominantly focuses on water-based recreation and water quality. As a result, the economic impacts of changes to waterside space are often overlooked. This study used the contingent valuation method to determine public preference for the protection of lakeside quality, in terms of lake views, path quality and lakeside access, at two large freshwater lakes in Scotland (Loch Lomond and Loch Leven). The aim of the study was to estimate willingness to pay among a sample of adults in Scotland $(\mathrm{n}=1056)$ for the protection of lakeside quality. Results indicate that the majority of respondents are willing to pay for the preservation of lakeside quality at each lake. Based upon the most conservative estimates obtained, mean willingness to pay for the protection of lakeside quality was $£ 12.06$ per household per year at Loch Lomond and $£ 8.44$ at Loch Leven. These findings provide valuable economic data and suggest that changes to waterside space at destination water bodies have nationally important economic impacts. Greater consideration of the economic impact of changes to lakeside space is recommended in order to develop cost-effective and socially optimal water resource management policies at large freshwater lakes.

Key words: Contingent valuation method; Stated preference; Lakeside space; Willingness to pay (WTP); Lake management; Valuation gap 


\subsection{Introduction}

Approximately $90 \%$ of all surface freshwater on earth is contained in natural or man-made lakes (Shiklomanov and Rodda, 2003). Humans derive a range of direct and indirect benefits from freshwater lakes which contribute to well-being (Reynaud and Lanzanov, 2017). These benefits can be related to a set of ecosystem services, including regulating (e.g. water purification), provisioning (e.g. fish production), supporting (e.g. nutrient cycling) and cultural (e.g. recreational activities) services (Millennium Ecosystem Assessment, 2005; Costanza et al., 2017). Quantifying the economic value of freshwater ecosystem services has become an increasingly important priority for policy makers since the implementation of the European Union's Water Framework Directive (WFD) (Directive/2000/60/EC). The WFD aims to achieve good ecological status (GES) for all water bodies in EU member states and requires the social and economic impacts of water policies related to achieving GES to be considered in the formation of catchment management plans (Vlachopoulou et al., 2014). Indeed, understanding the economic value of freshwater ecosystem services is an important element of designing socially optimal water resource management policies (Xu et al., 2018). However, empirically estimating the economic value of freshwater ecosystem services is challenging as these services frequently generate non-market benefits (Hanley et al., 2019).

Over recent decades, economists have developed a range of methods to value non-market benefits, which typically rely on the stated or revealed preferences of individuals (Mitchell and Carson, 1989). Revealed preference approaches determine economic values by observing actual behaviour, and linking this to the availability and / or quality of environmental resources such as rivers and forests. Stated preference methods determine economic values by analysing consumer behaviour in carefully designed hypothetical markets (Hanley and Czajkowski, 2019). Given that people are commonly unfamiliar with hypothetical markets and non-market goods, stated preference valuations often reflect a degree of uncertainty (Butler and Loomes, 2007). Where such uncertainty characterises the value people place on environmental enhancements, research suggests that respondents of stated preference surveys often prefer to provide a range of economic value statements rather than a single value (Mahieu et al., 2017). Understanding the size of this range of values or "valuation gap" is useful in interpreting the economic 
values derived from stated preferences approaches. However, few studies have attempted to identify what determines the size of this gap (Hanley et al., 2009; Smith et al., 2019).

The Contingent Valuation (CV) method is a survey-based stated preference approach, where respondents are asked to value changes to a non-market good such as water quality (Šebo et al., 2019), or air pollution (Hammit and Zhou, 2006). The CV method determines economic values of non-market goods by asking how much respondents are willing to pay or willing to accept in compensation for specified changes to the good in question. Measures of willingness to pay (WTP) and/or willingness to accept (WTA) allow a monetary value to be placed on the environmental gain or loss, which is an estimate of the underlying gain or loss in utility to the individual (Hanley et al., 2019). The CV method has been used extensively to determine the non-market value of improving water quality at lakes in various locations (Hunter et al., 2012; Bateman et al., 2005; Cooper et al., 2004; Van Houtven et al., 2014). While a substantial body of work seeks to determine the non-market benefits of changes to water quality and improvements to ecological status, less is known about changes to other important attributes of freshwater ecosystems.

Cultural ecosystem services, particularly the health and well-being benefits of spending time in the natural environment, have received increased attention across a number of disciplines in recent years. "Nature-health" research has predominantly focused on the health and well-being benefits of exposure to green space, which has been shown to improve both physical and mental health (Twohig-Bennett and Jones, 2018). The role of water bodies, recently termed "blue spaces", for promoting health improvements has received relatively less attention, yet a growing body of evidence suggests that exposure to freshwater can provide physical and mental health benefits, e.g. by reducing anxiety (Pearson et al., 2019) and encouraging physical activity (Vert et al., 2019). Emerging evidence that freshwater may play a direct role in facilitating health and well-being benefits suggests the value of cultural ecosystem services provided by water bodies may have been previously underestimated. This may partly explain why ecosystems services provided by lakes are recurrently undervalued in decisions related to their management and conservation (Reynaud and Lanzanova, 2017). 
Recent evidence suggests the majority of visitors to inland water bodies in England, UK do not make direct contact with water (Elliot et al., 2018) and that improved water quality does not necessarily enhance the ecosystem services offered by inland waters (Ziv et al., 2016). Health and well-being benefits related to blue space exposure commonly occur in terrestrial locations, e.g. due to non-water based physical activity (Vert et al., 2019), reduced psychological distress from viewing water (Nutsford et al., 2016) and social interaction in waterside environments (Bell et al., 2017). Consequently, water visibility and the condition of waterside spaces (e.g. path quality or the availability of open spaces) play an important role in the provision of health and well-being benefits, yet little is known empirically about the value of these attributes.

Having identified this knowledge gap, the present study adopted a CV approach to determine the nonmarket value of protecting "lakeside quality" in terms of water visibility, path quality and access to lakeside space at two large and popular freshwater lakes in Scotland: Loch Leven and Loch Lomond. The specific objectives were to: (i) quantify how the public value the protection of lakeside quality at two large water bodies in Scotland which are contrasting in physical characteristics, visitation numbers and water quality; (ii) determine how public willingness to pay for protecting lakeside quality is influenced by sociodemographic factors, visit characteristics and geographic location relative to the lake; (iii) establish what factors influence the size of the "valuation gap"; and (iv) inform future decision making processes at large freshwater lakes.

2.0 Case study descriptions

\subsection{Loch Lomond}

Loch Lomond is a large freshwater lake located in Central West Scotland, UK (56 $\left.05^{\prime} \mathrm{N} 4^{\circ} 34^{\prime} \mathrm{W}\right)$ (Fig. 1). The lake has a surface area of $71 \mathrm{~km}^{2}$ and approximately $153.5 \mathrm{~km}$ of shoreline with several beaches and lakeside settlements. Loch Lomond is located within the Loch Lomond and Trossachs National Park, which is protected under the National Parks (Scotland) Act (2000). The site is classified under a variety of conservation designations, including as a National Scenic Area (NSA), RAMSAR site, National Nature Reserve (NNR) and Special Protected Area (SPA). Loch Lomond Woods are 
designated as a Special Area of Conservation (SAC) due to the presence of western acidic oak woodland. Loch Lomond offers diverse recreational opportunities and receives approximately seven million visitor days and four million visitors per year, making it of one of the most popular sites for recreation in Scotland (Friends of Loch Lomond, 2019). The lake is surrounded by designated walking routes and cycle tracks and offers a variety of water-based recreational opportunities including swimming, boating, angling and water sports.

\subsection{Loch Leven}

Loch Leven is a shallow nutrient-rich freshwater lake located in Perthshire, Scotland, UK $\left(56^{\circ} 12^{\prime} \mathrm{N}\right.$, $3^{\circ} 22^{\prime} \mathrm{W}$ ) (Fig. 1). The lake has a surface area of $13 \mathrm{~km}^{2}$ and mean depth of $3.9 \mathrm{~m}$ with multiple sections that exceed 22 m (Hedger et al., 2002). In recent decades, Loch Leven has been adversely affected by nutrient inputs from surrounding commercial sources and rural septic tanks causing cyanobacterial blooms which can lead to water quality failing to meet World Health Organisation (WHO) standards for safe recreational usage (Hunter et al., 2010). The conservation importance of the lake is evidenced by its designation as a National Nature Reserve (NNR), a Site of Special Scientific Interest (SSSI), a Special Protected Area (SPA) and a RAMSAR site. Loch Leven receives approximately 200,000 visitors per year and visitor numbers are increasing annually (Reid et al., 2016). The lake is surrounded by a number of small beaches and a $22 \mathrm{~km}$ path which is popular among walkers, dog walkers and cyclists. Bird watching is also popular due to the presence of notable bird species, e.g. pink-footed goose (Anser brachyrhynchus), shoveler (Anas clypeata), gadwall (Anas strepera), goldeneye (Bucephala clangula) and cormorant (Phalacrocorax carbo), whilst angling is popular due to the presence of brown trout (Salmo trutta).

\footnotetext{
*** Insert Fig. 1***
} 


\subsection{Valuation Scenario}

The basis of any CV research is a valuation scenario which should be realistic and credible (Johnston et al., 2017). A hypothetical valuation scenario was developed to account for the objectives of this study and to take into account the differing physical characteristics of Loch Lomond and Loch Leven. The valuation scenario proposed an increase in management costs at either lake due to the need to respond to overgrowing native vegetation and increased visitor numbers. Overgrowing vegetation and increased visitor numbers provided a realistic and uncontroversial mechanism to reduce lake visibility, deteriorate path quality and limit lakeside access. A new, hypothetical lakeside management plan was thus proposed for selected areas of each lake to protect "lakeside quality" by focusing on three key issues: (1) maintaining path quality by remediating overgrowing vegetation and damage from increased footfall; (2) retaining current lake views from recreational areas and walking routes by managing overgrowing vegetation; (3) preserving access to lakeside spaces by managing aquatic and terrestrial vegetation growth. Such management plans would require additional funding from Scottish taxpayers, which generated a credible payment scenario. Further details of the valuation scenario are outlined in section 3.3.

\subsection{Methodology}

\subsection{Survey development and administration}

Individual CV surveys were designed for Loch Lomond and Loch Leven. The content and questions of both surveys were almost identical with the exception of small technicalities related to the differing characteristics of each site. Participants for both surveys were recruited via the Qualtrics online panel (www.qualtrics.com/uk/) which is made up of adults resident in the UK. After passing screening questions to confirm eligibility for the study (i.e. residing in Scotland), panel members were randomly directed to either survey on the Qualtrics online platform. The proposed extent of the hypothetical market, i.e. the group of people whose welfare could be affected by the changes at each lake being valued in the study (Mitchell and Carson, 1989), was selected as nationwide (Scotland-wide). A sample 
size of 500 respondents for each case study site was targeted in the sampling period (14th - 22nd August 2018), which is similar to recent nationwide CV studies that have been carried out in Scotland (Kuhfuss et al., 2016).

The survey instrument was designed in accordance with suggested best practice (Johnston et al., 2017). Prior to submission, the CV scenario and survey instrument were subject to rigorous qualitative and quantitative pre-testing. Qualitative pre-testing involved multiple focus groups made up of non-users (n $=3)$ and users $(n=4)$ of each lake in locations close to each site and further afield to account for the opinions of the wider population in Scotland. The valuation scenario and a series of landscape visualisations designed to convey visual changes were reviewed by academic experts in freshwater ecosystems from the University of Stirling $(n=7)$ and organisations involved in managing each lake (n $=2$ ) to ensure the survey content was accurate and credible. Quantitative pre-testing consisted of a pilot study of 100 responses (50 per lake) from Scottish households via the Qualtrics online panel outlined above. The pre-testing process assisted in refining the valuation scenario, ensuring the survey instrument was readable and selecting appropriate payment values for eliciting WTP.

\subsection{Background information and engagement with each lake}

Prior to the survey itself, respondents were provided with background information that outlined the objectives of the survey and how the results would be used. A policy consequentiality script was included to incentivise respondents to reveal their true preferences (Vossler and Watson, 2013; Czajkowski et al., 2017). The consequentiality script stated that the survey results would be shared with the Scottish Government and relevant policy makers to inform future management plans for either lake and other water bodies across Scotland. A similar script was adopted by Needham and Hanley (2019a) in a CV study of flood defence in Scotland.

The survey was divided into five sections. In section one, respondents were asked a variety of questions about their usage of water bodies in general. These questions had two purposes; to provide intellectual stimuli prior to more cognitively challenging questions at later stages in the survey and to collect data 
on factors that may influence WTP (Whitehead, 2016). The second section of the survey focused on behaviours specifically related to each lake. Respondents were presented with text outlining the conservation status, recreational opportunities and visitor numbers at each lake in order to provide context to the valuation scenario (Johnston et al., 2017). Respondents were then asked a variety of questions regarding their previous visits to the lake including visit frequency, visit duration and what activities were undertaken during visits.

\subsection{Status quo and valuation scenario}

Section three introduced the valuation scenario and presented the status quo and "take action" options. Respondents were made aware that the costs of managing either lake were increasing in the near future due to increased pressure from rising visitor numbers and overgrowing native vegetation. Without additional management, each site would degrade in terms of loss of views of the waterbody from pathways, reduced lakeside access due to aquatic and terrestrial vegetation overgrowth and path deterioration due to erosion from increased footfall. A range of "managed" (current) and "unmanaged" landscape visualisations were included to convey each element of degradation after 10 years, if additional management procedures were not carried out (Fig. 2). Managed images consisted of photographs taken on publicly accessible land and from a height of $1.65 \mathrm{~m}$ to simulate views from a human perspective. Unmanaged images were generated by a professional landscape architect using photo realistic layers of path deterioration and native vegetation. Visualisations are a common aid in CV studies and have been adopted to convey landscape changes due to windfarm projects (Kipperberg et al., 2019; Einarsdóttir et al., 2019), riverside regeneration (Verbič et al., 2016) and forest management strategies (Madureira et al., 2011).

Section four of the survey provided the contingent valuation scenario and question. Respondents were presented with a detailed description of the objectives of the new lakeside management plan. The lakeside management plan would last 10 years and would ensure path quality, lakeside access and lake views were preserved in their current condition. It was made clear to respondents that if the lakeside 
management plan did not go ahead, the impacts of vegetation overgrowth and path deterioration proposed in the "unmanaged" images were likely to occur, representing the status quo / baseline option (Johnston et al., 2017). The lakeside management plan consisted of areas of lakeside space management, view management and path management and these were depicted in a series of maps and textually.

$$
* * * \text { Insert Fig. 2*** }
$$

\subsection{Eliciting willingness-to-pay}

Respondents were informed that the current land managers would pay for $80 \%$ of the costs of the new lakeside management plan if it went ahead, with the remaining $20 \%$ of funding coming from increases in income tax that would be stored in a ring-fenced fund. Some water related contingent valuation studies in Scotland have adopted local taxes as payment vehicles, however, these have focused on scenarios which predominantly impact local communities (Needham and Hanley, 2019a; Hunter et al, 2012). Income tax provides a plausible payment vehicle for this study given that it is shared between all members of the sample and has been used in previous nationwide CV research in Scotland (Kuhfuss et al., 2016). Furthermore, lakeside spaces at Loch Lomond and Loch Leven are partly managed by government funded organisations and income tax, therefore, provides an appropriate and realistic payment vehicle.

The next section of the survey used two questions to gauge respondents WTP for the new lakeside management plan. Firstly, respondents were asked if they were willing to pay anything, even a small amount, in additional annual income tax to help fund the new lakeside management plan. Respondents who were willing to contribute were presented with a payment ladder with values ranging from $£ 0.5$ (50p) to £120. Payment ladder values were determined based on qualitative and quantitative pre-testing. For each payment value, respondents could respond by selecting "Yes" if they would be definitely willing to pay the amount in additional income tax annually to help fund the new plan, "No" if they were definitely not willing to pay the amount or "Unsure" if they were uncertain if they would be willing 
to pay the amount or not. The payment ladder valuation format was chosen to capture respondent uncertainty in their maximum willingness to pay (Hanley et al., 2009).

\subsection{Attitudinal and sociodemographic questions}

The final section of the survey included a range of statement-based questions to determine the environmental, cultural and health related importance of lakes in Scotland to each respondent. Based on a five point Likert scale (Strongly Disagree, Disagree, Neither, Agree, Strongly Agree) respondents were asked how much they agreed with statements related to water bodies and health, tourism, conservation and national identity (Fig. 3). Respondents were also presented with a five point Likert scale (Very Unconfident, Unconfident, Neither, Confident, Very Confident) to gauge perceived payment and policy consequentiality (Fig. 4). Policy consequentiality is the belief that responses to the survey will affect the supply of the environmental good in question and payment consequentiality is the belief that the respondent's stated WTP will affect how much they actually have to pay for the good, should it be provided (Zawojska et al., 2019). The survey concluded with sociodemographic questions (e.g. age, gender and household income), since such factors commonly influence WTP (Whitehead, 2016).

\subsection{Statistical analysis}

All statistical analysis was carried out in Stata (version 15.1). A logistic regression model or logit model was used to analyse whether a respondent was willing to pay $(\mathrm{WTP}>£ 0)$ or not $(\mathrm{WTP}=£ 0)$. The determinants of WTP were analysed using an interval regression model. The payment card approach adopted in this study allows WTP responses to be elicited as a range. The highest payment value that a respondent is definitely willing to pay is the most conservative estimate, otherwise known as lowerbound WTP. The lowest payment value that a respondent is definitely not willing to pay is classified as upper-bound WTP - this is the least conservative estimate. However, the true WTP value may fall between lower-bound and upper-bound WTP and selecting either for analysis may result in 
underestimating or overestimating WTP (Cameron and Huppert, 1989). Interval regression uses the lower-bound and upper-bound responses on the payment card as the dependent variables, minimising the potential of over or underestimating WTP.

$$
\text { *** Insert Table } 1 * * *
$$

The final modelling approach to identify the determinants of whether a respondent was willing to pay or not and the amount a respondent was willing to pay (Equation 1) consisted of multiple explanatory variables (Table 1). The stated preference literature suggests that the valuation of an environmental good is impacted by a variety of sociodemographic factors and the relationship between the respondent and the good in question. Economic theory and a wide range of stated preference studies indicate that WTP increases with rising income (Barbier et al, 2017). Several studies have also indicated that membership of an environmental group is a significant determinant of WTP (Needham and Hanley, 2019a; Dahal et al., 2018). Respondents who directly use the environmental good in question tend to value changes higher than those who do not use the good and as distance between the site in question and the residence of the respondent increases, WTP tends to decrease, particularly in the case of users (Bateman et al., 2006).

$W T P i=\beta_{0}+\beta_{1}$ INCOME $+\beta_{2}$ ENVGROUP $+\beta_{3}$ DISTANCE $+\beta_{4}$ USER $+\beta_{5}$ DURATION + $\beta_{6}$ POLICY_CON $+\beta_{7}$ PAY_CON $+\beta_{8}$ TOURISM $+\beta_{9} I D E N T I T Y+\varepsilon i$

Value may also arise from beliefs and behaviours that are not directly related to the good in question as, familiarity with a topic or environmental good (e.g. blue spaces in general) may make valuing a good at a specific site more informed (Kniivilä, 2006). Perceived payment and outcome consequentiality were included in the interval regression explaining WTP variation, since from Zawojska et al. (2019) it was expected that WTP would increase with policy consequentiality and decrease with payment consequentiality. Explanatory variables related to attitudinal responses and blue space usage and engagement were also tested to identify the best fitting model. Additional explanatory variables were selected based on an evaluation of Akaike information criterion (AIC) and Bayesian 
information criterion (BIC) (Šebo et al., 2019). Variance inflation factors (VIF) were analysed during the development of each final model to test for multicollinearity among explanatory variables.

In previous contingent valuation literature, the valuation gap $(V G)$ or uncertainty range is defined as the difference between upper and lower-bound WTP (Smith et al., 2019; Hanley et al., 2009). Given that the values in the payment card used in this study are not equally spaced, taking an absolute value of the valuation gap carries some assumption as the size of the valuation gap may be overestimated in the higher end of the payment card, where there are larger gaps between payment values. To account for any overestimation in the valuation gap as a result of the payment card format, the valuation gap was taken as a percentage of upper-bound willingness to pay (Voltaire et al., 2013) and can be denoted as stated in Equation 2:

$V G i=\left(\frac{U W T P i-L W T P i}{U W T P i}\right) * 100$

Where VGi is the valuation gap and UWTPi and LWTPi are the upper and lower-bound WTP responses indicated by the respondent. This approach provides a valuation gap that is relative to the payment card choices of uncertainty faced by the responded. Respondents who did not select "Unsure" to any values on the payment card were excluded from the analysis as any differences between upper and lowerbound WTP may have occurred as a result of the payment card format, rather than preference uncertainty.

An OLS regression model was developed to understand the determinants of the valuation gap (Hanley et al., 2009). Independent variables (Equation 3) were selected for the modelling process based on the stated preference literature. Previous research has indicated that the age and income of a respondent can affect uncertainty regarding the valuation of environmental goods (Voltaire et al., 2013). Based on previous work, it was anticipated that respondents who have used each site in the last year and those who reside closer to each site will report a lower valuation gap as they are likely to be more familiar with the environmental good in question (Hanley et al., 2009). There were no priors on the direction or significance of any effect of perceived consequentiality on the valuation gap, but this seemed to be an interesting effect to investigate empirically. 
$V G i=\beta_{0}+\beta_{1} I N C O M E+\beta_{2} U S E R+\beta_{3} A G E+\beta_{4}$ DISTANCE $+\beta_{5}$ PAY_CON +

$\beta_{6}$ POLICY_CON $+\varepsilon i$

4.0 Results

\subsection{Descriptive statistics}

In total, 1108 survey responses were received from the online panel. After reviewing all initial responses, 24 were removed due to missing information and 28 were removed due to illogical payment card responses (e.g. where a respondent was willing to pay a higher value on the payment card but not a lower value) resulting in a final sample of 1056 for the econometric analysis. A subsample for each lake was created based on the version of the survey completed by the respondent. The final sample was made up of 534 responses to the Loch Lomond version of the survey and 522 responses to the Loch Leven version. On average, respondents took 13 minutes to complete the Loch Lomond version and 15 minutes to complete the Loch Leven survey. The sociodemographic characteristics of both subsamples (Table 2) were representative of the adult population in Scotland according to important measured characteristics. The modal household income category for each subsample was $£ 20,000$ - $£ 30,000$ per annum, which aligns with the median household income in Scotland - 223,000 (Scottish Government, 2019). The population of Scotland has a slight majority of females (52\%) (National Records of Scotland, 2019), the Loch Leven subsample was highly representative (52\%) and the Loch Lomond subsample was less representative (54\%) but reflected the gender balance in the population. The modal age category of each subsample was $40-45$ which is highly representative of the median age for males (42) and females (41) in Scotland (National Records of Scotland, 2019).

$* * *$ Insert Table $2 * * *$

Table 3 provides summary statistics related to sample usage of Loch Lomond and Loch Leven, and how respondents engage with blue spaces in general. During the last year (since August 2018) over half (53\%) of the Loch Lomond subsample had visited the site. The national importance of Loch Lomond as recreational site is highlighted by the majority of the sample - which is drawn from all Scottish households, not just those that are located near Loch Lomond - having visited the lake in the last year. 
The number of respondents who had visited the site in the last year was lower in the Loch Leven subsample (31\%). A small portion of each subsample lived within 10 miles each the site, approximately 9\% for Loch Lomond and 5\% for Loch Leven. The modal distance category (i.e. how far a respondent lived from the lake they were questioned on) was $30-50$ miles for both subsamples. The majority (approximately 90\%) of respondents in both subsamples had visited a blue space in the last year, with most visits lasting between 30 minutes and an hour.

$* * *$ Insert Table $3 * * *$

\subsection{Attitudinal responses}

Regarding lochs specifically, the majority of respondents of each subsample strongly agreed that conserving lochs was important for wildlife in Scotland, that lochs were important for attracting tourists to Scotland and that lochs were an important part of Scotland's national identity (Fig. 3). Collectively, the strong positive responses suggested possible rationales for non-use and existence values among respondents. Around half of respondents in the Loch Lomond (47\%) and Loch Leven (44\%) subsample agreed that blue space could play an important role in improving health and well-being.

$$
\text { *** Insert Fig. 3*** }
$$

\subsection{Policy and payment consequentiality}

The majority of respondents from the Loch Leven and Loch Lomond subsample elicited positive (confident or very confident) responses to perceived outcome consequentiality (Fig. 4). Most respondents in both subsamples believed that the management plan proposed in the contingent valuation scenario would go ahead. Only a small portion of respondents in each subsample - Loch Lomond (15\%) and Loch Leven (14\%) - selected "unconfident" or "very unconfident" to the policy consequentiality question. For payment consequentiality at Loch Lomond, most respondents $(42 \%)$ in the subsample were confident that their income tax would increase to help fund the management plan. This trend was 
not present in the Loch Leven subsample as "neither" was the modal category (39\%). However, more respondents elicited positive responses (confident or very confident $-42 \%$ ) than negative responses (unconfident or very unconfident - 19\%) for payment consequentiality in the Loch Leven subsample.

$$
\text { *** Insert Fig. 4*** }
$$

\subsection{Public willingness-to-pay}

The majority of respondents in both subsamples were willing to contribute a positive amount towards the preservation of lakeside quality at Loch Leven and Loch Lomond (see Fig. 5). For Loch Lomond $76 \%$ had a WTP $>0$ and for Loch Leven $65 \%$ had a WTP $>0$. Respondents' reasons for not being willing to pay are summarised in Table 4 and were divided into protest (coded $\mathrm{P}$ ) and true-zero responses (coded TZ). Protest responses suggest a respondent has rejected part of the valuation exercise, such as the choice of payment vehicle, whereas true zero responses indicates the respondent accepts the valuation scenario but has no effective demand for the good (Meyerhoff and Liebe, 2006). The main reasons for not being prepared to pay towards the protection of lakeside quality at Loch Lomond and Loch Leven were not being able to afford to pay (55\% and 47\%, respectively), the belief that it was not their responsibility to pay to offset damages at Loch Lomond / Loch Leven (21\% and 16\%, respectively) and preferring to spend household income on other things ( $8 \%$ and $15 \%$, respectively). Protest responses accounted for approximately $20 \%$ of zero responses in both subsamples and were removed for further analysis since these responses do not tell us whether or how much people cared about the environmental changes being valued (Jones et al., 2008).

\section{*** Insert Table $4 * * *$}

A summary of lower-bound, midpoint and median WTP for each subsample is included in Table 5. Based upon lower-bound WTP, which is the maximum amount each respondent stated they were definitely willing to pay, mean WTP was $£ 12.06(\mathrm{SE}=1.03)$ per household per annum for protecting lakeside quality at Loch Lomond. Mean-lower bound WTP for the protection of lakeside quality at Loch Leven (based on lower bound WTP) was $£ 8.44(\mathrm{SE}=0.79)$ per household per annum. Midpoint WTP 
(the midpoint between the lower and upper-bound on WTP as reflected in the payment ladder) for Loch Lomond was $£ 21.76(\mathrm{SE}=1.33)$ and $£ 15.62(\mathrm{SE}=1.09)$ for Loch Leven.

*** Insert Table 5***

*** Insert Fig. $5 * * *$

\subsection{Determinants of willingness-to-pay}

A logistic regression (Table 6) was carried out to identify what independent variables influenced whether a respondent was willing to pay anything (WTP $>£ 0$ ) for the protection of lakeside quality at either site or not $(\mathrm{WTP}=£ 0)$. Household income was significantly associated with being willing to pay for Loch Leven $(\mathrm{p}<0.1)$ and Loch Lomond $(\mathrm{p}<0.01)$, with a stronger effect being found for the Loch Lomond subsample. A significant negative association was present between being willing to pay and distance $(\mathrm{p}<0.01)$ in the Loch Leven subsample, suggesting those living further from the site were more likely to elicit a zero WTP response. A significant positive association was identified between both consequentiality questions for each subsample. For the Loch Lomond subsample, a highly significantly positive association was identified for both policy $(\mathrm{p}<0.01)$ and payment consequentiality $(p<0.01)$. The effect of policy consequentiality $(p<0.01)$ was stronger in the Loch Leven subsample, however, the effect of payment consequentiality $(\mathrm{p}<0.1)$ was weaker.

$$
* * * \text { Insert Table } 6 * * *
$$

Interval regression models were developed to identify how each of the selected independent variables influenced stated WTP in the Loch Lomond and Loch Leven subsamples (Table 7). The selected sociodemographic variables had similar effects on WTP for both subsamples. A significant positive association was identified between household income and WTP for Loch Leven $(\mathrm{p}<0.01)$ and Loch Lomond $(\mathrm{p}<0.01)$, with a stronger effect being found for Loch Lomond. For the Loch Leven subsample, a significant positive association was present between membership of environmental group and WTP, with - all else being equal - environmental group members willing to pay $£ 6.33$ more than 
non-members $(\mathrm{p}<0.05)$. The "distance decay effect" suggests that as the distance between a respondent and an environmental good increases, WTP decreases (Lee, 2016). A small but significant distance decay was present in the Loch Lomond subsample with WTP decreasing as the distance a respondent lived from the site increased $(\mathrm{p}<0.01)$, but no such effect was found for Loch Leven. In the case of Loch Leven, a significant positive correlation between site usage in the last year and WTP was identified. Respondents who had visited Loch Leven in the last year were, all else being equal, willing to pay $£ 4.93$ more than respondents who had not visited $(\mathrm{p}<0.05)$. In contrast, a significant negative association was identified for the Loch Lomond subsample, with users - all else being equal - willing to pay $£ 4.71$ less than respondents who had not visited the site in the last year $(\mathrm{p}<0.1)$. The average duration of a respondents' visits to blue spaces was positively associated $(\mathrm{p}<0.01)$ with WTP for both subsamples.

A significant positive correlation was identified between WTP and perceived payment consequentiality in both Loch Lomond $(\mathrm{p}<0.1)$ and Loch Leven $(\mathrm{p}<0.05)$ subsamples. All else being equal, respondents who elicited positive responses (confident or very confident) to the payment consequentiality question were willing to pay more at Loch Lomond (£4.34) and Loch Leven (£3.88) than those who did not elicit positive responses (neither, unconfident or very unconfident). A significant positive association was identified between policy consequentiality and WTP in the Loch Leven subsample $(\mathrm{p}<0.01)$, with all else being equal, respondents who reported positive responses, willing to pay $£ 7.74$ more than respondents who did not select a positive policy consequentiality response. A significant positive association between respondents who strongly agreed that lochs represented an important part of Scotland's cultural identity and WTP was identified for the Loch Lomond subsample $(\mathrm{p}<0.1)$. For the Loch Leven subsample, respondents who strongly agreed that lochs were important for attracting tourists to Scotland elicited significantly higher WTP values than those who did not strongly agree with the statement $(\mathrm{p}<0.05)$.

$$
* * * \text { Insert Table } 7 * * *
$$

4.6 Determinants of the valuation gap 
The majority of respondents who were willing to pay for Loch Lomond (75\%) and Loch Leven (70\%) reported WTP as a range by selecting "Unsure" to one or more of values on the payment card. The valuation gap data was similarly distributed for both subsamples (Fig. 6). The mean valuation gap was $70.4 \%(\mathrm{SE}=0.94)$ for the Loch Lomond subsample and 71.0\% $(\mathrm{SE}=1.05)$ for the Loch Leven subsample (see Fig. 6). An OLS regression was carried out to identify what independent variables influenced the size of the valuation gap; that is, why some people are more uncertain about the value they place on protecting lakeside quality (Table 8). The results of the regression analysis suggest different factors influenced the size of the valuation gap in the two subsamples. For the Loch Lomond subsample, a negative and significant association $(\mathrm{p}<0.05)$ was present between age and the size of the valuation gap, suggesting older respondents were more certain about their preferences. Usage of either lake was positively associated with the size of the valuation gap for both subsamples; however, neither result was significant. Payment consequentiality was significantly negatively associated $(\mathrm{p}<$ 0.05) with the valuation gap in the Loch Leven subsample. All else being equal, respondents who believed their responses to be consequential were $4 \%$ more certain than those who did not believe their responses were consequential. In the Loch Leven subsample, a positive and significant association ( $\mathrm{p}<$ 0.05) was identified between distance to the lake and the valuation gap, suggesting respondents who lived further away from the lake were more uncertain in their responses.

$$
\begin{aligned}
& * * * \text { Insert Table } 8 * * * \\
& * * * \text { Insert Fig. } 6 * * *
\end{aligned}
$$

\subsection{Discussion}

As noted at the outset of this paper, previous valuation studies of lakes have mainly focused on the economic impact of improving water quality (Huang et al., 2013; Cooper et al., 2004; Moore et al., 2009) or increasing water based recreation opportunities (Meyerhoff et al., 2019; Rolfe and Prayaga, 2007). However, with growing understanding of how humans interact with water bodies or blue spaces, it has become apparent that the majority of visits to water bodies do not involve direct water contact 
and that benefits are often accrued from engagement with water from terrestrial locations e.g. observing views of water (Nutsford et al., 2016) or undertaking non-water based physical activity such as walking or cycling by the waterside (Vert et al., 2019). Consequently, improving water quality may not be the highest value investment in terms of enhancing the ecosystem services offered by inland waters (Ziv et al., 2016). From a health and well-being perspective, the importance of lakeside space is well documented; however, it is often overlooked in research concerned with the valuation of ecosystem services offered by lakes. The present study thus investigated public preferences for protecting current lakeside quality, in terms of lakeside access, lake views and path quality, at two large destination lakes in Scotland.

The values obtained in this study provide novel contributions to a growing database of economic values related to the ecosystem services provided by lakes (Reynaud and Lanzanova, 2017). Based on the most conservative estimates obtained, mean WTP per annum for the protection of lakeside quality at Loch Lomond and Loch Leven was $£ 12.06(\mathrm{SE}=1.03)$ and $£ 8.44(\mathrm{SE}=0.79)$, respectively. These findings are comparable to recent $\mathrm{CV}$ studies focusing on improving water quality at lakes in Europe. For example, Šebo et al (2019) reported a mean WTP of $£ 9.50$ per annum for improvements in water quality at an urban lake in Slovakia. A more direct comparison is offered by the work of Hunter et al. (2012) who estimate local residents are WTP between $£ 9.99$ and $£ 12.23$ per annum to reduce the number of days per year that water quality (in terms of cyanobacteria) poses a human health risk at Loch Leven. Whilst the comparison of welfare estimates obtained in CV studies is difficult due to differing elicitation methods, payment vehicles and the framing of the environmental good in question, these comparisons contextualise the findings of the present study by showing similarities to welfare estimates obtained for improving water quality. The findings can assist the decision-making processes at water bodies by demonstrating that changes to waterside space have an important non-market economic impact, relative to improving water quality and that both users and non-users derive welfare benefits from the protection of lakeside space. Economic analysis that focuses solely on water quality and excludes changes to waterside space, may neglect the effects of a policy on the provision of cultural ecosystem services that 
do not require direct water contact and consequently, result in uneconomical and suboptimal water resource management policies.

Kuhfuss et al. (2016) used the CV method to estimate the value of maintaining access to a variety of publicly funded historic monuments in Scotland, which like the two lakes in this study, are also valued by individuals who do not routinely visit the sites. Their study found that $48 \%$ of the sample were willing to contribute towards maintaining public access to a variety of historic monuments and mean WTP was $£ 2.79$ per annum. The proportion of responses willing to contribute, and mean WTP, were greater for both nationally important lakes in this study than those reported for maintaining public access to historic sites. Using Scotland as a case study, the observed preferences among users and non-users of two large samples may inform future debates on the allocation of public funding between nationally important built and natural environmental resources.

Contingent valuation studies obtain an economic value from a sample of individuals and these values need to be aggregated to the relevant population to obtain the total value of the good in question (Mitchell and Carson, 1989). In this study, both subsamples were representative of the adult population in Scotland based on a number of observable characteristics, so a coarse aggregation of WTP across the 2.45 million households in Scotland was performed. Per year the aggregate value for protecting lakeside quality at Loch Lomond based on mean lower-bound WTP was $£ 20,678,000$ and $£ 53,312,000$ based on mean midpoint WTP. Per year the aggregate WTP value for Loch Leven was $£ 29,547,000$ and based on mean lower-bound WTP and $£ 38,269,000$ based on mean midpoint WTP. These substantial aggregate values demonstrate the significant economic value of protecting lakeside quality at large freshwater lakes. These values should better inform decision-makers at large freshwater lakes in Scotland and further afield via benefits transfer approaches, mainly in terms of providing robust economic data that was not available prior to this study.

As expected respondents with higher household income were significantly more likely to be willing to pay and willing to pay significantly more for the protection of lakeside quality than those with lower household income, reinforcing a well-established trend in stated preference literature and economic theory (Barbier et al, 2017). Indeed, a recent meta-analysis of CV studies on improving the ecological 
status of water bodies suggests income to be a frequently significant driver of WTP (Tyllianakis and Skuras, 2016). The identification of a distance decay effect has been replicated in a wide variety of CV studies including for rivers (Jørgensen et al., 2013). This finding is contrary to a recent study demonstrating a positive distance decay effect in relation to WTP for water quality improvements at an urban lake in Slovakia (Šebo et al., 2019). Understanding the distance decay effect at large destination water bodies can assist debates between key stakeholders, national government and local authorities, by helping to answer critical questions such as who gets the benefits from investing in blue spaces, and who should bear the cost of managing these spaces. Investigating distance decay effects can also assist in gauging the extent of the market i.e. the group of people whose welfare could be affected by the changes at each lake (Smith, 1993). The findings of this study suggest that although welfare benefits decrease with greater distance to Loch Lomond, the welfare benefits obtained from nationally important freshwater lakes span far wider than the local scale adopted in previous valuation studies (Šebo et al., 2019; Hunter et al., 2012).

The interval regression models suggest that people who spend longer periods of time at blue spaces when they visit are willing to pay greater amounts for the protection of lakeside quality. It may be the case that respondents who visit for longer periods of time feel more familiar with the lakeside settings in question due to greater familiarity with similar site characteristics at other blue spaces (Kniivilä, 2006). In both subsamples, respondents who were confident or very confident that their survey response would affect how much they actually have to pay for the protection of lakeside quality at Loch Leven or Loch Lomond, should it be provided were WTP more than those that were not confident. This is contrary to the result reported in Zawojska et al (2019) and it may be the case that respondents used their responses to perceived consequentiality as another way to express their positive preferences for the management plan (Needham and Hanley, 2019b). In the Loch Leven subsample, respondents who reported positive policy consequentiality responses, reported higher WTP than those who did not select a positive policy consequentiality response, which is in accord with the findings of Zawojska et al., (2019). 
Respondents who had visited Loch Leven in the last year (users) were willing to pay significantly more than those who had not visited (non-users). This result is in line with previous studies that have identified higher WTP among users of the environmental good in question (Bateman et al., 2006). Contradictorily, users of Loch Lomond were willing to pay significantly less than non-users. This result was unexpected, however, the high non-use value of Loch Lomond is supported by the positive responses to statement-based questions regarding the preservation of lakes in Scotland as this is seen to support tourism and protect wildlife. There are a number of other reasons as to why the protection of lakeside quality at Loch Lomond may be valued among non-users. Firstly, people who have not visited the site in the last year may value the option to visit the site in its current state in the future. Secondly, non-use value may be induced by altruism, where value is motivated by safeguarding usage for others, such as one's own children or future generations. Thirdly, non-use value may be motivated purely by knowing that an environmental good exists in a certain state, irrespective of potential future use (Nijkamp et al., 2008). Existence value is often associated with environmental goods with unique characteristics or cultural importance (Hanley et al., 2019) and Loch Lomond falls within these categories. The negative association observed between visiting Loch Lomond in the last year and WTP may also suggest that usage is not an effective indicator of WTP for protecting nationally important natural resources. Furthermore, it may be the case that lower WTP among users of Loch Lomond comes as they already make a financial contribution towards the management of the site (Rodella et al., 2019) e.g. through car park charges or investing in services offered by current land managers.

Economic values for environmental goods often exhibit a degree of uncertainty (Butler and Loomes, 2007) and when given the option, many people favour reporting a range of economic values rather than a specific value (Mahieu et al., 2017). The present study also found that the majority of respondents preferred to report WTP as a range of values. The findings contribute to a small but growing body of research dedicated to understanding what determines the size of this range or valuation gap. In the Loch Leven subsample, distance between the household and lake was significantly associated with the size of valuation gap. This finding is in alignment with previous research showing location relative to the site influences the size of the valuation gap (Hanley et al., 2009). In both subsamples, no significant 
association was observed between using the site in the last year and the size of the valuation gap. These findings are in contrast to results obtained by Hanley et al. (2009) for beach quality improvements in Scotland, and cast doubt over the assumption that familiarity with the environmental good in question is associated with higher payment certainty and that usage is a good proxy for familiarity. Respondents who believed their income tax would be increased if the management plan at Loch Leven went ahead reported significantly lower valuation gaps than respondents who were unconfident that income tax would be increased. The negative relationship identified between payment consequentiality and the size of the valuation gap represents a novel finding, although it is not clear what the behavioural mechanism behind such a relationship might be.

\subsection{Conclusion}

Bodies of freshwater offer valuable ecosystem services; however, there remains significant and ongoing debate on their economic value and how this value is impacted by water resource management policies. Economic valuations of lake ecosystems often focus on water quality or changes to water-based recreation opportunities. The emerging blue space, health and well-being research agenda has highlighted the importance of waterside space in facilitating cultural ecosystem services at inland water bodies and yet waterside space is overlooked in the economic valuation literature. Findings from this CV study of two large freshwater lakes have important and internationally relevant implications. Firstly, the findings suggest that changes to lakeside space have important non-market economic impacts and, therefore, greater consideration of these changes can improve and refine decision-making processes at large water bodies. Secondly, by determining the non-market value of protecting lakeside quality, valuable economic data is provided that can inform decision making at large lakes across Scotland and further afield. Thirdly, by determining how the benefits of protecting lakeside quality are shared across a sample of users and non-users, the findings can inform decisions related to resource allocation and debates around who benefits from and, therefore, who should fund the management of nationally important water bodies. Fourthly, the study provides insight on the determinants of the valuation gap, by highlighting the complex role that consequentiality has on preference uncertainty. The present study classifies lakeside quality as a package of goods due to lack of previous research on the economic 
impact of changes to lakeside space. Consequently, the study does not provide an understanding of preferences between path quality, lake views and lakeside access, which may further inform management processes. Future research using the choice experiment (CE) method is needed to understand how attributes of lakeside quality interact with one another.

Acknowledgments

The Scottish Government Hydro Nation Scholars Programme provided funding to support this research. We would like to thank Scottish Natural Heritage (NatureScot), HERE+NOW landscape architects and all focus group participants for their assistance in developing the contingent valuation scenario and survey instrument. We would also like to thank the editor and three anonymous reviewers for their role in improving the quality of the manuscript. The survey instrument is available upon request from the corresponding author. 


\subsection{References}

Barbier, E. B., Czajkowski, M. and Hanley, N. (2017) 'Is the Income Elasticity of the Willingness to Pay for Pollution Control Constant?', Environmental and Resource Economics. Springer Netherlands, 68(3), pp. 663-682. doi: 10.1007/s10640-016-0040-4.

Bateman, I. J. et al. (2005) 'Economic valuation of policies for managing acidity in remote mountain lakes: Examining validity through scope sensitivity testing', Aquatic Sciences. Birkhäuser-Verlag, 67(3), pp. 274-291. doi: 10.1007/s00027-004-0744-3.

Bateman, I. J. et al. (2006) 'The aggregation of environmental benefit values: Welfare measures, distance decay and total WTP', Ecological Economics, 60(2), pp. 450-460. doi: 10.1016/j.ecolecon.2006.04.003.

Bell, S. et al. (2017) 'The importance of nature in mediating social and psychological benefits associated with visits to freshwater blue space', Landscape and Urban Planning. Elsevier, 167, pp. 118-127. doi: 10.1016/J.LANDURBPLAN.2017.06.003.

Bergstrom, J. C. and Loomis, J. B. (2017) 'Economic valuation of river restoration: An analysis of the valuation literature and its uses in decision-making', Water Resources and Economics. Elsevier B.V., 17, pp. 9-19. doi: 10.1016/j.wre.2016.12.001.

Butler, D. J. and Loomes, G. C. (2007) 'Imprecision as an account of the preference reversal phenomenon', American Economic Review, 97(1), pp. 277-297. doi: 10.1257/aer.97.1.277.

Cameron, T. A. and Huppert, D. D. (1989) 'OLS versus ML estimation of non-market resource values with payment card interval data', Journal of Environmental Economics and Management, 17(3), pp. 230-246. doi: 10.1016/0095-0696(89)90018-1.

Cooper, P., Poe, G. L. and Bateman, I. J. (2004) 'The structure of motivation for contingent values: a case study of lake water quality improvement', Ecological Economics. Elsevier, 50(1-2), pp. 69-82. doi: 10.1016/J.ECOLECON.2004.02.009.

Costanza, R. et al. (2017) 'Twenty years of ecosystem services: How far have we come and how far do we still need to go?', Ecosystem Services. Elsevier, 28, pp. 1-16. doi: 10.1016/J.ECOSER.2017.09.008.

Czajkowski, M. et al. (2017) 'Addressing empirical challenges related to the incentive compatibility of stated preferences methods', Journal of Economic Behavior \& Organization. North-Holland, 142, pp. 47-63. doi: 10.1016/J.JEBO.2017.07.023.

Dahal, R. P. et al. (2018) 'Estimating the willingness to pay to preserve waterfront open spaces using contingent valuation', Land Use Policy. Pergamon, 78, pp. 614-626. doi: 10.1016/J.LANDUSEPOL.2018.07.027.

Einarsdóttir, S. R., Cook, D. and Davíðsdóttir, B. (2019) 'The contingent valuation study of the wind farm Búrfellslundur - Willingness to pay for preservation', Journal of Cleaner Production. Elsevier, 209, pp. 795-802. doi: 10.1016/J.JCLEPRO.2018.10.156.

Elliott, L. R. et al. (2018) 'Recreational visits to marine and coastal environments in England: Where, what, who, why, and when?', Marine Policy. Pergamon, 97, pp. 305-314. doi: 10.1016/J.MARPOL.2018.03.013.

Friends of Loch Lomond \& The Trossachs (2019). Fact File. [online] Lochlomondtrossachs.org.uk. Available at: http://www.lochlomondtrossachs.org.uk/fact-file [Accessed 22 June 2019]. 
Hammit, J. K. and Zhou, Y. (2006) 'The economic value of air-pollution-related health risks in China: A contingent valuation study', in Environmental and Resource Economics, pp. 399-423. doi: 10.1007/s10640-005-3606-0.

Hanley, N. and Czajkowski, M. (2019) 'The Role of Stated Preference Valuation Methods in Understanding Choices and Informing Policy', Review of Environmental Economics and Policy. doi: 10.1093/reep/rez005.

Hanley, N., Kriström, B. and Shogren, J. F. (2009) 'Coherent Arbitrariness: On Value Uncertainty for Environmental Goods', Land Economics. University of Wisconsin Press, pp. 41-50. doi: $10.2307 / 27647864$.

Hanley, N., Shogren, J. F. and White, B. (Benedict) (2019) Introduction to environmental economics. Oxford, UK: Oxford University Press.

Hedger, R. D. et al. (2002) 'Coupling remote sensing with computational fluid dynamics modelling to estimate lake chlorophyll-a concentration', Remote Sensing of Environment. Elsevier, 79(1), pp. 116122. doi: 10.1016/S0034-4257(01)00244-9.

Huang, L. et al. (2013) 'Public demand for remediating a local ecosystem: Comparing WTP and WTA at Hongze Lake, China', Lake and Reservoir Management, 29(1), pp. 23-32. doi: 10.1080/10402381.2013.767866.

Hunter, P. D. et al. (2010) 'Hyperspectral remote sensing of cyanobacterial pigments as indicators for cell populations and toxins in eutrophic lakes', Remote Sensing of Environment. Elsevier, 114(11), pp. 2705-2718. doi: 10.1016/J.RSE.2010.06.006.

Hunter, P. D. et al. (2012) 'The effect of risk perception on public preferences and willingness to pay for reductions in the health risks posed by toxic cyanobacterial blooms', Science of The Total Environment. Elsevier, 426, pp. 32-44. doi: 10.1016/J.SCITOTENV.2012.02.017.

Johnston, R. J. et al. (2017) 'Contemporary Guidance for Stated Preference Studies', Journal of the Association of Environmental and Resource Economists. University of Chicago PressChicago, IL, 4(2), pp. 319-405. doi: 10.1086/691697.

Jones, N., Sophoulis, C. M. and Malesios, C. (2008) 'Economic valuation of coastal water quality and protest responses: A case study in Mitilini, Greece', Journal of Socio-Economics, 37(6), pp. 24782491. doi: 10.1016/j.socec.2007.06.002.

Jørgensen, S. L. et al. (2013) 'Spatially induced disparities in users' and non-users' WTP for water quality improvements - Testing the effect of multiple substitutes and distance decay', Ecological Economics. Elsevier, 92, pp. 58-66. doi: 10.1016/J.ECOLECON.2012.07.015.

Kipperberg, G. et al. (2019) 'The impact of wind turbines on local recreation: Evidence from two travel cost method - contingent behavior studies', Journal of Outdoor Recreation and Tourism. Elsevier, 25, pp. 66-75. doi: 10.1016/J.JORT.2018.11.004.

Kniivilä, M. (2006) 'Users and non-users of conservation areas: Are there differences in WTP, motives and the validity of responses in CVM surveys?', Ecological Economics, 59(4), pp. 530-539. doi: 10.1016/j.ecolecon.2005.11.017.

Kuhfuss, L., Hanley, N. and Whyte, R. (2016) 'Should historic sites protection be targeted at the most famous? Evidence from a contingent valuation in Scotland', Journal of Cultural Heritage. Elsevier Masson, 20, pp. 682-685. doi: 10.1016/J.CULHER.2016.01.004. 
Lee, J. (2016) 'Income and distance-decay effects on willingness to pay estimated by the contingent valuation method', Journal of Environmental Planning and Management. Routledge, 59(11), pp. 1957-1981. doi: 10.1080/09640568.2015.1100984.

Madureira, L. et al. (2011) 'Assessing forest management strategies using a contingent valuation approach and advanced visualisation techniques: A Portuguese case study', Journal of Forest Economics. Elsevier, 17(4), pp. 399-414. doi: 10.1016/J.JFE.2011.04.001.

Mahieu, P.A. et al. (2017) 'Interval bidding in a distribution elicitation format', Applied Economics, 49(51), pp. 5200-5211. doi: 10.1080/00036846.2017.1302065.

Meyerhoff, J. and Liebe, U. (2006) 'Protest beliefs in contingent valuation: Explaining their motivation', Ecological Economics, 57(4), pp. 583-594. doi: 10.1016/j.ecolecon.2005.04.021.

Meyerhoff, J., Klefoth, T. and Arlinghaus, R. (2019) 'The value artificial lake ecosystems provide to recreational anglers: Implications for management of biodiversity and outdoor recreation', Journal of Environmental Management. Elsevier BV, 252, p. 109580. doi: 10.1016/j.jenvman.2019.109580.

Millennium Ecosystem Assessment (2005) "Ecosystems and Human Well-Being: Current State and Trends" Island Press, Washington, DC

Mitchell, R. C. and Carson, R. T. (1989) Using surveys to value public goods : the contingent valuation method. Washington, D.C: Resources for the Future.

Moore, R., Provencher, B. and Bishop, R. C. (2011) 'Valuing a spatially variable environmental resource: Reducing non-point-source pollution in Green Bay, Wisconsin', Land Economics. University of Wisconsin Press, 87(1), pp. 45-59. doi: 10.3368/le.87.1.45.

National Records of Scotland (2019). Area Profiles | Census Data Explorer | Scotland's Census. [online] Scotlandscensus.gov.uk. Available at: https://www.scotlandscensus.gov.uk/odsweb/area.html [Accessed 12 Sep. 2019].

Needham, K. and Hanley, N. (2019a) 'Valuing a managed realignment scheme: What are the drivers of public willingness to pay?', Ocean \& Coastal Management. Elsevier, 170, pp. 29-39. doi: 10.1016/J.OCECOAMAN.2018.12.015.

Needham, K. and Hanley, N. (2019b) 'Prior knowledge, familiarity and stated policy consequentiality in contingent valuation', Journal of Environmental Economics and Policy. Informa UK Limited, pp. 1-20. doi: 10.1080/21606544.2019.1611481.

Nijkamp, P., Vindigni, G. and Nunes, P. A. L. D. (2008) 'Economic valuation of biodiversity: A comparative study', Ecological Economics, 67(2), pp. 217-231. doi: 10.1016/j.ecolecon.2008.03.003.

Nutsford, D. et al. (2016) 'Residential exposure to visible blue space (but not green space) associated with lower psychological distress in a capital city', Health \& Place. Pergamon, 39, pp. 70-78. doi: 10.1016/J.HEALTHPLACE.2016.03.002.

Pearson, A. L. et al. (2019) 'Effects of freshwater blue spaces may be beneficial for mental health: A first, ecological study in the North American Great Lakes region.', PloS one. Public Library of Science, 14(8), p. e0221977. doi: 10.1371/journal.pone.0221977.

Reid, D. et al (2016) The Management Plan for Loch Leven National Nature. Stirling, UK: Scottish Natural Heritage

Reynaud, A. and Lanzanova, D. (2017) 'A Global Meta-Analysis of the Value of Ecosystem Services Provided by Lakes', Ecological Economics. Elsevier, 137, pp. 184-194. doi:

10.1016/J.ECOLECON.2017.03.001. 
Rodella, I. et al. (2019) 'Willingness to pay for management and preservation of natural, semi-urban and urban beaches in Italy', Ocean and Coastal Management. Elsevier Ltd, 172, pp. 93-104. doi: 10.1016/j.ocecoaman.2019.01.022.

Rolfe, J. and Prayaga, P. (2007) 'Estimating values for recreational fishing at freshwater dams in Queensland', Australian Journal of Agricultural and Resource Economics, 51(2), pp. 157-174. doi: 10.1111/j.1467-8489.2007.00369.x.

Scottish Government (2019) "Poverty and income inequality in Scotland: 2015-2018” Edinburgh, UK: Scottish Government

Šebo, J., Gróf, M. and Šebová, M. (2019) 'A contingent valuation study of a polluted urban lake in Košice, Slovakia: The case of the positive distance effect', Journal of Environmental Management. Academic Press, 243, pp. 331-339. doi: 10.1016/J.JENVMAN.2019.05.051.

Shiklomanov, I. A. and Rodda, J. C. (2004) World water resources at the beginning of the twenty-first century, Choice Reviews Online. Cambridge, UK: Cambridge University Press. doi: 10.5860/choice.41-4063.

Smith, G. S., Day, B. H. and Bateman, I. J. (2019) 'Preference uncertainty as an explanation of anomalies in contingent valuation: coastal management in the UK', Regional Environmental Change. Springer Verlag. doi: 10.1007/s10113-019-01501-y.

Smith, V. K. (1993) 'Nonmarket valuation of environmental resources: an interpretive appraisal', Land Economics, 69(1), pp. 1-26. doi: 10.2307/3146275.

Twohig-Bennett, C. and Jones, A. (2018) 'The health benefits of the great outdoors: A systematic review and meta-analysis of greenspace exposure and health outcomes', Environmental Research. Academic Press, 166, pp. 628-637. doi: 10.1016/J.ENVRES.2018.06.030.

Tyllianakis, E. and Skuras, D. (2016) 'The income elasticity of Willingness-To-Pay (WTP) revisited: A meta-analysis of studies for restoring Good Ecological Status (GES) of water bodies under the Water Framework Directive (WFD)', Journal of Environmental Management. Academic Press, 182, pp. 531-541. doi: 10.1016/J.JENVMAN.2016.08.012.

Van Houtven, G. et al. (2014) 'Combining expert elicitation and stated preference methods to value ecosystem services from improved lake water quality', Ecological Economics. Elsevier, 99, pp. 4052. doi: 10.1016/J.ECOLECON.2013.12.018.

Verbič, M., Slabe-Erker, R. and Klun, M. (2016) 'Contingent valuation of urban public space: A case study of Ljubljanica riverbanks', Land Use Policy. Pergamon, 56, pp. 58-67. doi:

10.1016/J.LANDUSEPOL.2016.04.033.

Vert, C. et al. (2019) 'Health Benefits of Physical Activity Related to An Urban Riverside

Regeneration', International Journal of Environmental Research and Public Health. Multidisciplinary Digital Publishing Institute, 16(3), p. 462. doi: 10.3390/ijerph16030462.

Vlachopoulou, M. et al. (2014) 'The potential of using the Ecosystem Approach in the implementation of the EU Water Framework Directive', Science of the Total Environment. Elsevier, 470-471, pp. 684-694. doi: 10.1016/j.scitotenv.2013.09.072.

Voltaire, L., Pirrone, C. and Bailly, D. (2013) 'Dealing with preference uncertainty in contingent willingness to pay for a nature protection program: A new approach', Ecological Economics, 88, pp. 76-85. doi: 10.1016/j.ecolecon.2013.01.009. 
Vossler, C. A. and Watson, S. B. (2013) 'Understanding the consequences of consequentiality: Testing the validity of stated preferences in the field', Journal of Economic Behavior \& Organization. North-Holland, 86, pp. 137-147. doi: 10.1016/J.JEBO.2012.12.007.

Whitehead, J. C. (2006) 'A Practitioner's Primer on the Contingent Valuation Method', in Alberini, A. and Kahn, J. R. (eds) Handbiook on Contingent Valuation. Cheltenham, UK: Edward Elgar Publishing, pp. 66-91.

$\mathrm{Xu}, \mathrm{X}$. et al. (2018) 'Lake-wetland ecosystem services modeling and valuation: Progress, gaps and future directions', Ecosystem Services. Elsevier, 33, pp. 19-28. doi: 10.1016/J.ECOSER.2018.08.001.

Zawojska, E., Bartczak, A. and Czajkowski, M. (2019) 'Disentangling the effects of policy and payment consequentiality and risk attitudes on stated preferences', Journal of Environmental Economics and Management. Academic Press Inc., 93, pp. 63-84. doi: 10.1016/j.jeem.2018.11.007.

Ziv, G. et al. (2016) 'Water Quality Is a Poor Predictor of Recreational Hotspots in England', PLoS ONE, 11(11). doi: 10.1371/journal.pone.0166950. 

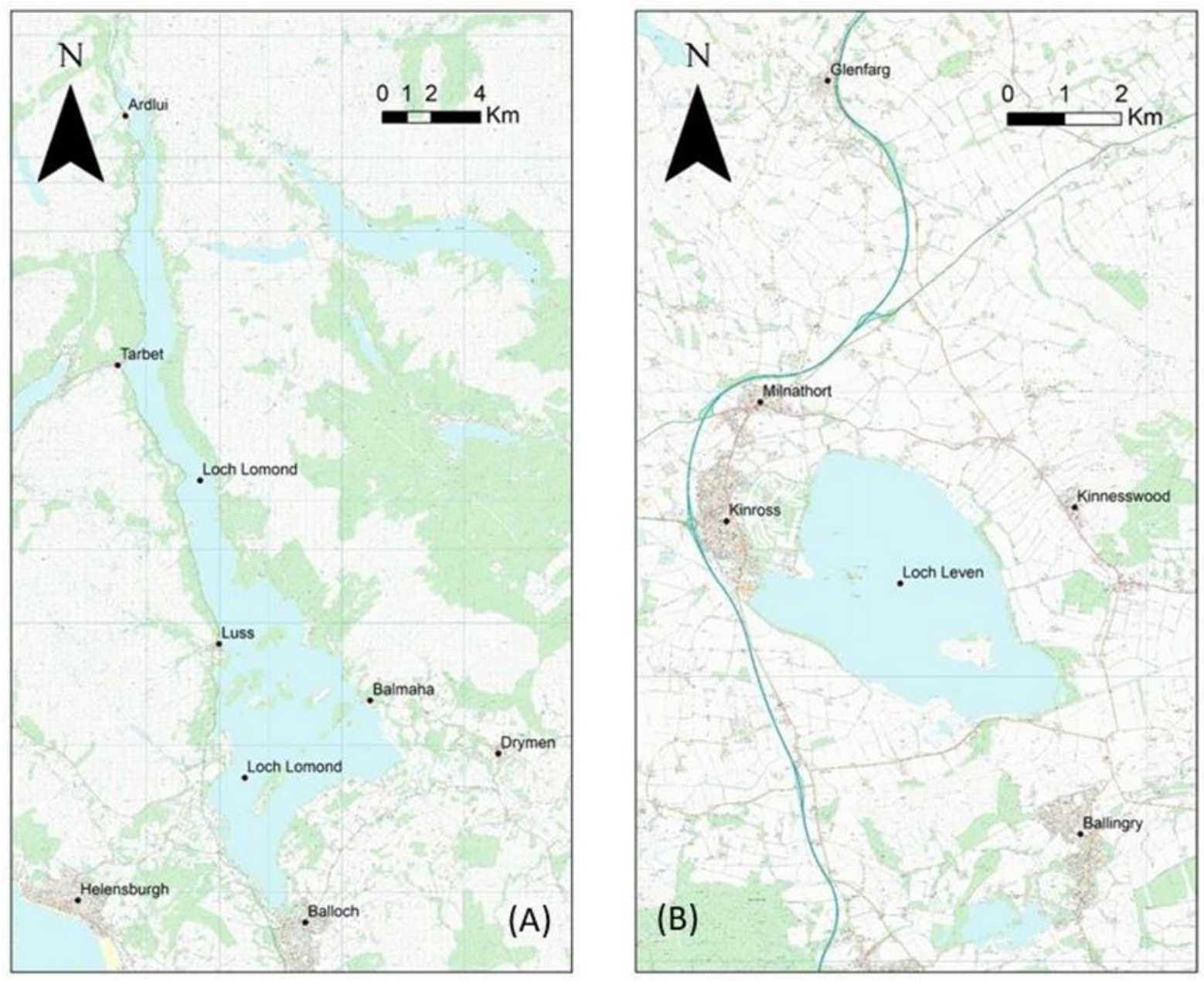

Fig. 1: Maps of Loch Lomond (A) and Loch Leven (B) 

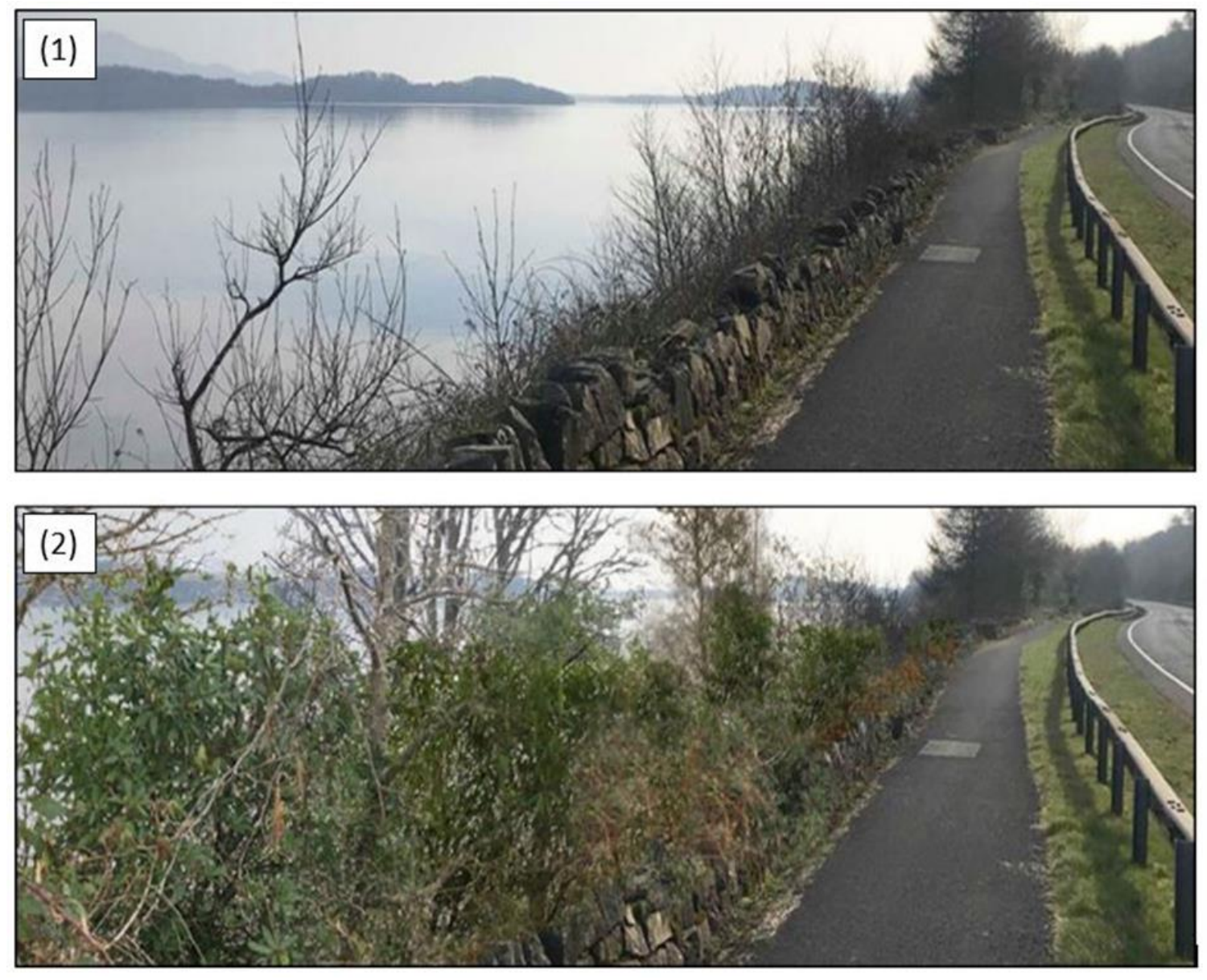

Fig. 2: Example of visualisation: Managed (1) and unmanaged (2) lake views at Loch Lomond 


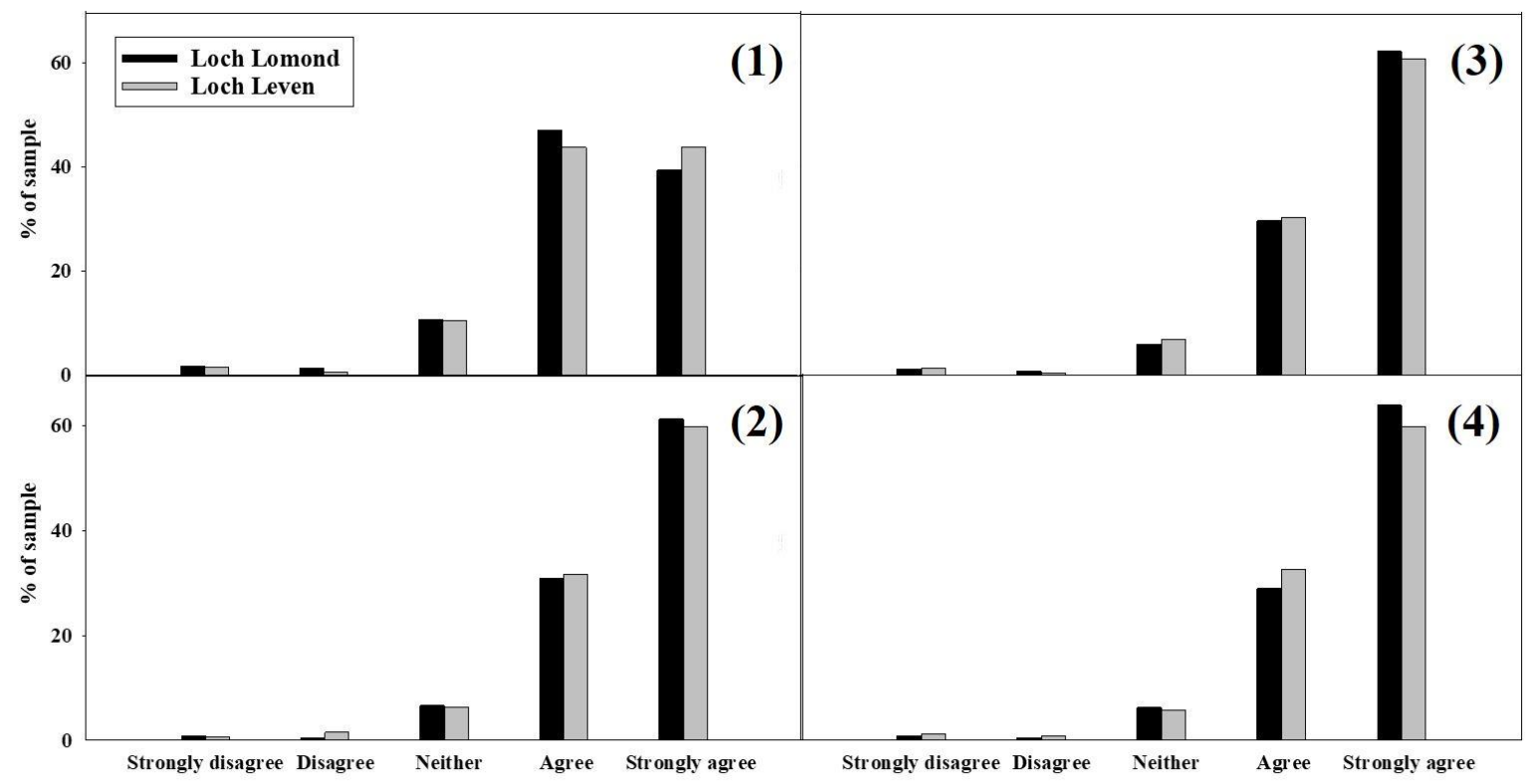

Fig. 3: Responses to statement based questions: (1) Spending time near water such as the sea, coasts, rivers lochs, lakes, canals etc.) can play an important role in improving health and well-being; (2) I believe that the conservation and protection of lochs is important for wildlife in Scotland; (3) I believe that lochs are important for attracting tourists to Scotland; and (4) I believe that lochs are important elements of Scotland's national identity. 

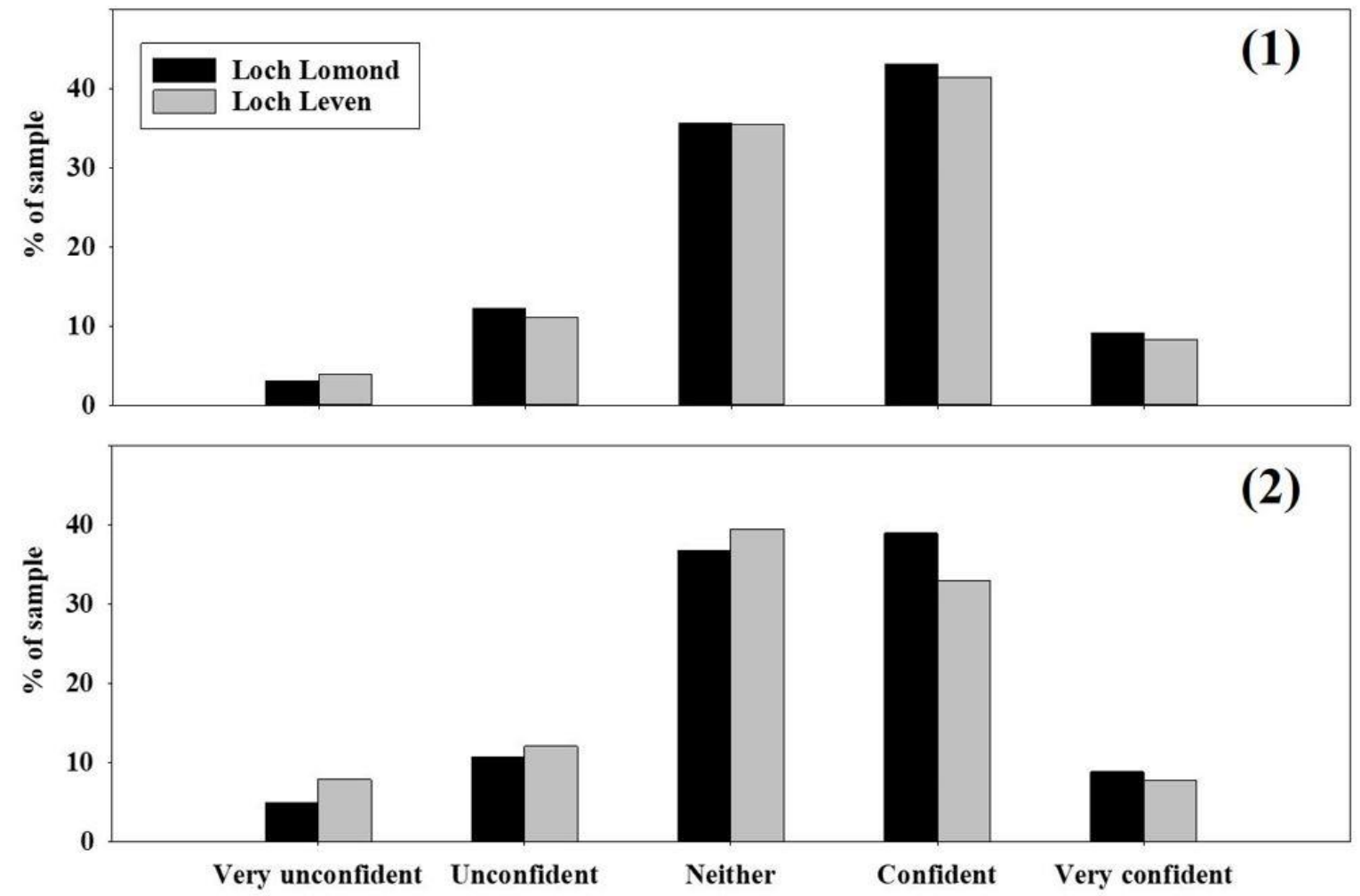

Fig. 4: Responses to policy (1) and payment (2) consequentiality questions: (1) How confident are you that the new Lochside Management Plan for Loch Leven will be carried out? (2) How confident are you, that if the new Lochside Management Plan for Loch Leven goes ahead, that your income tax would rise to help pay for it? 


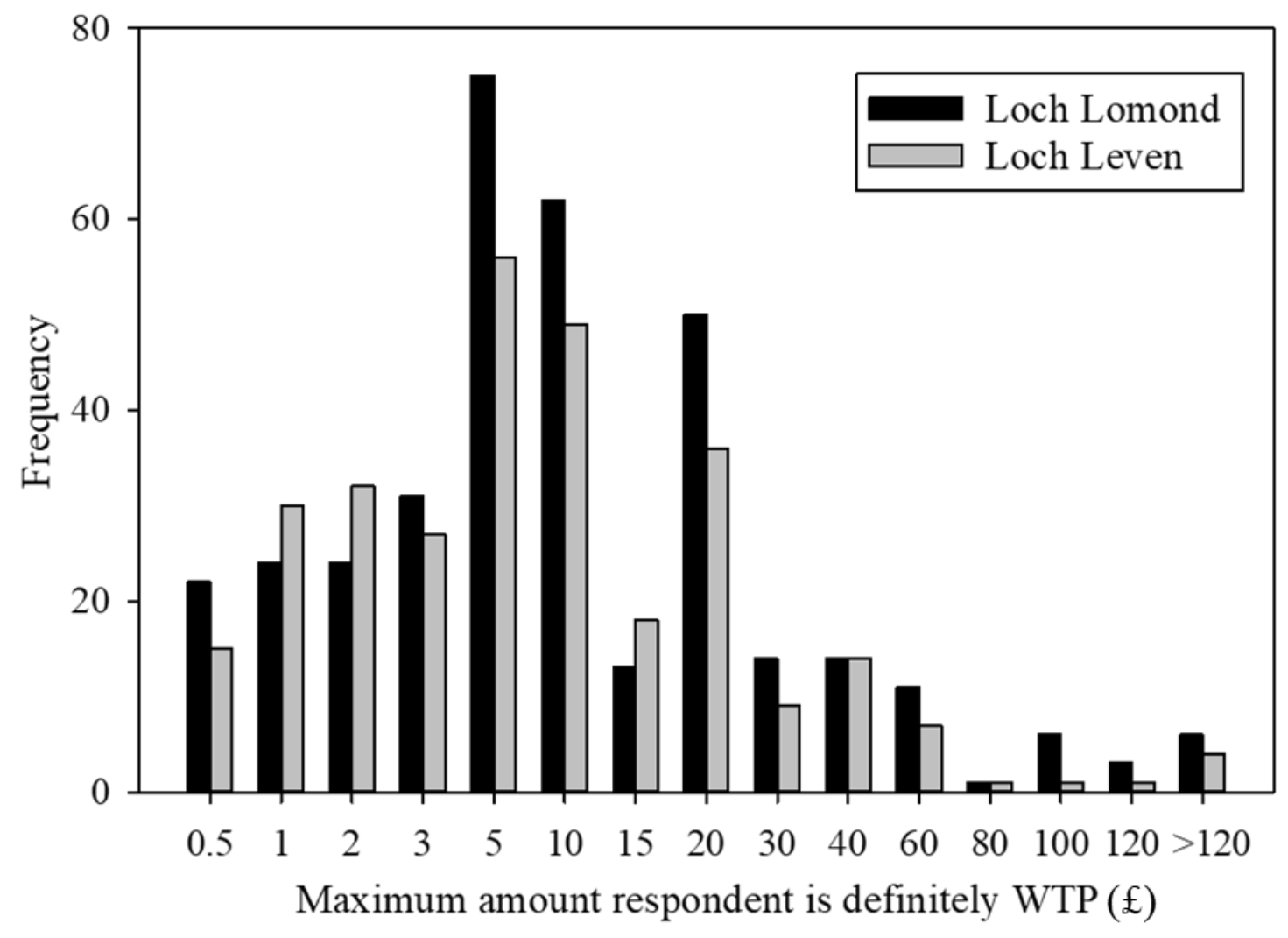

Fig. 5: Highest payment value that respondent would definitely be willing to pay (lower-bound WTP) 

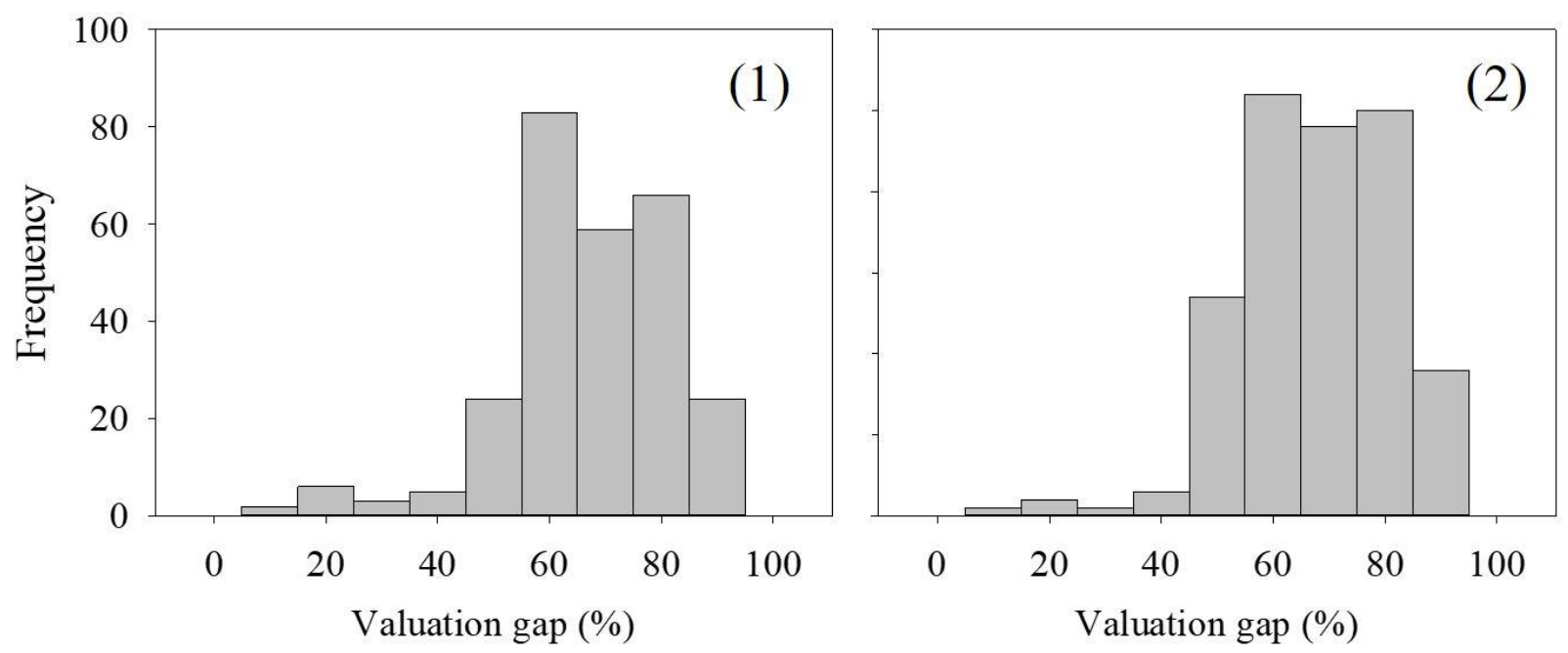

Fig. 6: Distribution of valuation gap for (1) Loch Lomond and (2) Loch Leven 
Table 1: Description of independent variables used in the modelling process

\begin{tabular}{|c|c|}
\hline Variable & Description \\
\hline INCOME & $\begin{array}{l}\text { Household income ranging from under } £ 15 \mathrm{k}-£ 100 \mathrm{k} \text { per annum: } \\
\text { ( } 9 \text { categories, midpoint of each category used in regression) }\end{array}$ \\
\hline AGE & $\begin{array}{l}\text { Age categories ranging from } 18 \text { - over } 65 \text { : } \\
\text { ( } 6 \text { categories, midpoint of each category used in regression) }\end{array}$ \\
\hline ENVGROUP & Member of an environmental group $(0=$ no $/ 1=$ yes $)$ \\
\hline DISTANCE & $\begin{array}{l}\text { Natural } \log \text { of distance to site ranging from } 0-5 \text { miles to over } 200 \text { miles: } \\
\text { (10 categories, midpoint of each category used in regression) }\end{array}$ \\
\hline USER & Has visited the lake in last year $(0=$ no $/ 1=$ yes $)$ \\
\hline DURATION & $\begin{array}{l}\text { Duration of time spent when visiting any BS } \\
\text { From } 0 \text { minutes to more than } 480 \text { minutes ( } 8 \text { hours): } \\
\text { ( } 10 \text { categories, midpoint of each category used in regression) }\end{array}$ \\
\hline POLICY_CON & $\begin{array}{l}\text { "How confident are you that the new Lochside Management Plan for Loch X } \\
\text { will be carried out?" } \\
(0=\text { strongly disagree, disagree or neither } / 1=\text { agree or strongly agree })\end{array}$ \\
\hline PAY_CON & $\begin{array}{l}\text { "How confident are you, that if the new Lochside Management Plan for Loch } \\
\text { X goes ahead, that your income tax would rise to help pay for it?" } \\
(0=\text { strongly disagree, disagree or neither } / 1=\text { agree or strongly agree })\end{array}$ \\
\hline TOURISM & $\begin{array}{l}\text { "I believe that lochs (lakes) are important for attracting tourists to Scotland." } \\
(0=\text { strongly disagree, disagree, neither or agree } / 1=\text { strongly agree })\end{array}$ \\
\hline IDENTITY & $\begin{array}{l}\text { "I believe that lochs are important elements of Scotland's national identity." } \\
(0=\text { strongly disagree, disagree, neither or agree / } 1=\text { strongly agree })\end{array}$ \\
\hline
\end{tabular}


Table 2: Descriptive statistics for sociodemographic information: Loch Lomond $(n=534)$ and Loch Leven $(\mathrm{n}=522)$

\begin{tabular}{|c|c|c|}
\hline & $\begin{array}{c}\% \text { of } \\
\text { sample } \\
\text { (Lomond) }\end{array}$ & $\begin{array}{c}\% \text { of } \\
\text { sample } \\
\text { (Leven) }\end{array}$ \\
\hline \multicolumn{3}{|l|}{ Income } \\
\hline Under $£ 15,000$ & 21.05 & 19.54 \\
\hline$£ 15,000-£ 20,000$ & 14.66 & 13.41 \\
\hline$£ 20,000-£ 30,000$ & 25.19 & 20.88 \\
\hline$£ 30,000-£ 40,000$ & 15.79 & 19.16 \\
\hline$£ 40,000-£ 50,000$ & 10.53 & 11.11 \\
\hline$£ 50,000-£ 60,000$ & 4.32 & 6.51 \\
\hline$£ 60,000-£ 80,000$ & 5.26 & 5.94 \\
\hline$£ 80,000-£ 100,000$ & 2.26 & 1.92 \\
\hline Over $£ 100,000$ & 0.94 & 1.53 \\
\hline \multicolumn{3}{|l|}{ Gender } \\
\hline Male & 45.76 & 47.69 \\
\hline Female & 54.24 & 52.31 \\
\hline \multicolumn{3}{|l|}{ Environmental group } \\
\hline No & 89.70 & 88.31 \\
\hline Yes & 10.30 & 11.69 \\
\hline \multicolumn{3}{|l|}{ Age } \\
\hline $18-25$ & 10.15 & 11.88 \\
\hline $26-34$ & 18.23 & 12.84 \\
\hline $35-44$ & 23.12 & 22.61 \\
\hline $45-54$ & 18.61 & 21.84 \\
\hline $55-64$ & 15.31 & 20.50 \\
\hline 65 or older & 14.47 & 10.34 \\
\hline \multicolumn{3}{|l|}{ Highest education level } \\
\hline Secondary school & 37.78 & 27.20 \\
\hline College & 27.44 & 32.76 \\
\hline University (undergraduate) & 24.81 & 28.93 \\
\hline University (postgraduate) & 9.96 & 11.11 \\
\hline \multicolumn{3}{|l|}{ Relationship status } \\
\hline Divorced & 11.24 & 11.11 \\
\hline Married & 52.25 & 55.75 \\
\hline Single (never married) & 33.71 & 29.50 \\
\hline Widowed & 2.81 & 3.64 \\
\hline
\end{tabular}


Table 3: Descriptive statistics for non-sociodemographic variables: Loch Lomond $(n=534)$ and Loch Leven $(\mathrm{n}=522)$

\begin{tabular}{|c|c|c|}
\hline & $\begin{array}{c}\% \text { of } \\
\text { sample } \\
\text { (Lomond) }\end{array}$ & $\begin{array}{c}\text { \% of } \\
\text { sample } \\
\text { (Leven) }\end{array}$ \\
\hline \multicolumn{3}{|l|}{ Visited site in last year } \\
\hline Yes & 52.62 & 31.03 \\
\hline No & 47.38 & 68.97 \\
\hline \multicolumn{3}{|c|}{ Distance to site from residence } \\
\hline Less than 5 miles & 4.49 & 2.11 \\
\hline 5 miles -10 miles & 4.87 & 3.26 \\
\hline 10 miles -20 miles & 9.74 & 7.09 \\
\hline 20 miles -30 miles & 11.99 & 11.30 \\
\hline 30 miles -50 miles & 18.35 & 20.88 \\
\hline 50 miles -70 miles & 13.11 & 16.86 \\
\hline 70 miles -100 miles & 15.73 & 16.09 \\
\hline 100 miles -150 miles & 7.68 & 10.15 \\
\hline 150 miles -200 miles & 8.43 & 5.56 \\
\hline Over 200 miles & 5.62 & 6.70 \\
\hline \multicolumn{3}{|c|}{ BS view from household } \\
\hline Yes & 26.40 & 28.16 \\
\hline No & 73.60 & 71.84 \\
\hline \multicolumn{3}{|c|}{ Average duration of $\mathrm{BS}$ visits } \\
\hline Never visit & 10.11 & 11.11 \\
\hline Less than 30 minutes & 10.49 & 12.45 \\
\hline 30 minutes -1 hour & 24.72 & 24.14 \\
\hline 1 hour -1.5 hours & 16.85 & 18.39 \\
\hline 1.5 hours -2 hours & 14.23 & 10.34 \\
\hline 2 hours -3 hours & 9.55 & 10.92 \\
\hline 3 hours -4 hours & 4.49 & 7.47 \\
\hline 4 hours -5 hours & 5.24 & 2.30 \\
\hline 5 hours -8 hours & 2.62 & 1.72 \\
\hline More than 8 hours & 1.69 & 1.15 \\
\hline \multicolumn{3}{|l|}{ Visits BS to socialise } \\
\hline Yes & 23.78 & 17.05 \\
\hline No & 76.22 & 82.95 \\
\hline \multicolumn{3}{|c|}{ Visits BS to interact with nature } \\
\hline Yes & 30.15 & 28.54 \\
\hline No & 69.85 & 71.46 \\
\hline
\end{tabular}


Table 4: Summary of true zero and protest responses

\begin{tabular}{llcc}
\hline Summary of zero bids & $\begin{array}{c}\text { \% of } \\
\text { TZ = True-zero response } \\
\text { P = Protest response }\end{array}$ & $\begin{array}{c}\text { (Lomond) } \\
\mathbf{n = 1 6 3}\end{array}$ & $\begin{array}{c}\text { \% of } \\
\text { sample } \\
\text { (Leven) } \\
\mathbf{n}=\mathbf{2 1 5}\end{array}$ \\
\hline TZ & I am not concerned about these changes at Loch Leven / Lomond & 1.23 & 2.33 \\
TZ & I do not believe we need to invest in the management of lochs. & 3.07 & 1.40 \\
TZ & I would like to contribute but cannot afford to. & 54.60 & 46.51 \\
TZ & I would prefer to spend my income on other things. & 7.98 & 14.88 \\
P & I do not want the management plan to go ahead. & 1.84 & 0.47 \\
P & I would need to know more about the plan to make a decision. & 6.75 & 6.98 \\
P & It is not my responsibility to invest in Loch Lomond. & 21.47 & 16.28 \\
& Other reason. & 3.07 & 11.16 \\
\hline
\end{tabular}


Table 5: Summary of WTP for the protection of lakeside quality

\begin{tabular}{lcc}
\hline Willingness to Pay Summary & Loch Lomond & Loch Leven \\
\hline Mean WTP (lower bound) (£) & 12.06 & 8.44 \\
SE & 1.03 & 0.79 \\
$95 \%$ CI & $10.04-14.08$ & $6.90-9.99$ \\
Median WTP (lower bound) (£) & 5.00 & 2.00 \\
& & \\
Mean WTP (mid-point) (£) & 21.76 & 15.62 \\
SE & 1.33 & 1.09 \\
$95 \%$ CI & $19.14-24.37$ & $13.48-17.77$ \\
Median WTP (mid-point) (£) & 10.00 & 6.00 \\
& & \\
Predicted WTP (interval regression) (£) & 18.72 & 12.77 \\
SE & 0.42 & 0.38 \\
$95 \%$ CI & $17.90-19.56$ & $12.01-13.52$ \\
Sample size (protest responses removed) & 483 & 471 \\
Number of true zero bids & 114 & 164 \\
\hline
\end{tabular}


Table 6: Logistic regression models for determining if respondent is willing to pay or not lakeside quality protection at Loch Lomond and Loch Leven

\begin{tabular}{lllll}
\hline Variable & \multicolumn{2}{l}{ Loch Lomond } & \multicolumn{2}{l}{ Loch Leven } \\
\hline INCOME & $0.02 * * *$ & $(0.01)$ & $0.01^{*}$ & $(0.01)$ \\
ENVGROUP & 0.17 & $(0.42)$ & 0.61 & $(0.38)$ \\
DISTANCE & -0.09 & $(0.13)$ & $-0.43^{* * *}$ & $(0.14)$ \\
USER & 0.08 & $(0.26)$ & 0.08 & $(0.26)$ \\
DURATION & 0.00 & $(0.00)$ & $0.00^{* *}$ & $(0.00)$ \\
POLICY_CON & $0.81^{* * *}$ & $(0.26)$ & $0.94^{* * *}$ & $(0.23)$ \\
PAY_CON & $0.76^{* * *}$ & $(0.26)$ & $0.46^{*}$ & $(0.24)$ \\
TOURISM & 0.43 & $(0.34)$ & $0.60^{*}$ & $(0.33)$ \\
IDENTITY & $0.68 * *$ & $(0.34)$ & $0.57 *$ & $(0.33)$ \\
Constant & -0.54 & $(0.62)$ & & \\
Observations & 485 & & 0.43 & $(0.62)$ \\
AIC & 467.75 & & 471 & \\
BIC & 509.59 & & 528.75 & \\
Log Likelihood & -223.87 & & 570.30 & \\
& & & -254.37 & \\
\hline
\end{tabular}

Note: Standard errors in parentheses: $* * * \mathrm{p}<0.01, * * \mathrm{p}<0.05,{ }^{*} \mathrm{p}<0.1$ 
Table 7: Interval regression models for WTP for lakeside quality protection at Loch Lomond and Loch Leven

\begin{tabular}{lllll}
\hline Variable & \multicolumn{2}{l}{ Loch Lomond } & \multicolumn{2}{l}{ Loch Leven } \\
\hline INCOME & $0.31^{* * *}$ & $(0.06)$ & $0.11^{* * *}$ & $(0.04)$ \\
ENVGROUP & 2.85 & $(3.79)$ & $6.33^{* *}$ & $(2.66)$ \\
DISTANCE & $-2.50^{* *}$ & $(1.21)$ & -0.98 & $(0.99)$ \\
USER & $-4.71^{*}$ & $(2.59)$ & $3.93^{* *}$ & $(1.97)$ \\
DURATION & $0.03^{* * *}$ & $(0.01)$ & $0.03^{* * * *}$ & $(0.01)$ \\
POLICY_CON & 2.01 & $(2.53)$ & $7.74^{* * *}$ & $(1.85)$ \\
PAY_CON & $4.34^{*}$ & $(2.56)$ & $3.88^{* *}$ & $(1.86)$ \\
TOURISM & -2.93 & $(3.45)$ & $6.06^{* *}$ & $(2.59)$ \\
IDENTITY & $8.94^{*}$ & $(3.50)$ & -0.06 & $(2.65)$ \\
Predicted WTP & 18.72 & $(0.42)$ & & \\
Constant & 10.95 & $(5.85)$ & 12.76 & $(0.38)$ \\
Observations & 485 & & -0.36 & $(4.61)$ \\
AIC & 2683.86 & & 471 & \\
BIC & 2729.84 & & 2722.48 & \\
Log Likelihood & -1330.93 & & 2768.19 & \\
& & & -1350.24 & \\
\hline
\end{tabular}

Note: Standard errors in parentheses: $* * * \mathrm{p}<0.01, * * \mathrm{p}<0.05, * \mathrm{p}<0.1$ 
Table 8: OLS regression models for determinants of the valuation gap

\begin{tabular}{lllll}
\hline Variable & \multicolumn{2}{l}{ Loch Lomond } & \multicolumn{2}{l}{ Loch Leven } \\
& \multicolumn{2}{l}{} & & \\
\hline & & & & \\
INCOME & 0.03 & $(0.05)$ & -0.06 & $(0.05)$ \\
DISTANCE & 1.65 & $(1.06)$ & $2.64 * *$ & $(1.17)$ \\
USER & 0.98 & $(2.20)$ & 2.22 & $(2.23)$ \\
AGE & $-1.29 * *$ & $(0.64)$ & 0.08 & $(0.71)$ \\
POLICY_CON & -2.95 & $(2.19)$ & -3.23 & $(2.32)$ \\
PAY_CON & -0.90 & $(2.22)$ & $-4.11^{* *}$ & $(2.27)$ \\
& & & & \\
Constant & 68.03 & $(5.40)$ & 65.70 & $(5.44)$ \\
Observations & 266 & & 211 & \\
AIC & 2230.96 & & 1745.26 & \\
BIC & 2256.05 & & -865.63 & \\
Log Likelihood & -1108.48 & & & \\
& & & & \\
\hline
\end{tabular}

Note: Standard errors in parentheses: $* * * \mathrm{p}<0.01, * * \mathrm{p}<0.05, * \mathrm{p}<0.1$ 